\title{
Panurethral strictures: a review of management options
}

\begin{abstract}
Introduction: Panurethral strictures represent a complex subgroup of urethral strictures. Lichen sclerosis is the commonest cause for these strictures. We outline the management of panurethral strictures in this review.

Material and Methods: Our institute is a tertiary referral center. We evaluated panurethral strictures (primary and redo cases) managed at our institute over the last 20 years (June 1995-June 2015) using single stage Kulkarni one- sided urethroplasty with oral mucosal graft. Patients with incomplete medical records were excluded from the study. Data was analysed for primary or redo case, age, cause of stricture, length of stricture, follow up and success rate. Success was defined as no requirement of any further intervention. Follow up was carried out every 3 months in the first year and every year thereafter. Follow up included clinical examination and uroflow. This is a non-analytic study and descriptive analysis was carried out.

Results: 318 (283 primary and 35 redo) cases of panurethral strictures were managed at our institute over last 20 years. Lichen sclerosis was seen in $184(57.84 \%)$ cases. $84.9 \%$ (primary $89.39 \%$ and redo $57.85 \%$ ) cases were successful. Age range of patients was 20-76 years (median 44.6 years) with stricture length from 10-19 cms. Follow up was at regular intervals using uroflow assessment. Median follow up was 59 months (range 6.4 to 192).

Conclusion: Lichen sclerosis is the commonest cause for panurethral strictures. Kulkarni one-sided panurethroplasty offers a single stage surgery with acceptable outcomes and avoids inclusion of genital skin as seen in staged procedures.
\end{abstract}

Volume 4 Issue $6-2017$

\section{Devang J Desai, Pankaj M Joshi, Subramanian lyer, Hazem Orabi, Sandesh Surana, Jyotsna Kulkarni, Sanjay B Kulkarni}

Kulkarni Endosurgery Institute and Reconstructive Urology Centre, India

Correspondence: Devang Desai, Department of Urology, Rajpath Society, Opposite Vanaz Engineering, Paud Road, Pune, India4I 1038,Email ddesai@toowoombaurology.com.au

Received: September 01, 2017| Published: June 19, 2017

\section{Introduction}

Panurethral stricture is a complex condition and represents the most challenging of urethral stricture disease. Most panurethral strictures occur due to lichen sclerosis. Multistage urethroplasty has been utilized to manage this condition in the past. Lichen sclerosis is a disease of genital skin, local skin flaps or staged urethroplasty is best avoided because the disease can recur in the tubularized urethra. We have now established a single stage urethroplasty utilising buccal mucosa.

\section{Materials and methods}

Our center is a tertiary referral center for reconstructive urology cases. We evaluated our database of panurethral strictures over the last 20 years (June 1995-June 2015). All patients with long segment urethral strictures involving penile and bulbar urethra which were suitable for reconstruction were included in the study. Patients with incomplete medical records were not included in this review. Data was analysed for primary or redo case, age, cause of stricture, length of stricture, follow up and success rate. Success was defined as no requirement of any further intervention. Follow up was carried out every 3 months in the first year and every year thereafter. Follow up included clinical examination and uroflow.

Patients with symptomatic poor flow less than $12 \mathrm{ml} / \mathrm{sec}$ and/or urinary tract infections were evaluated further with uroflowmetery, urethrography and endoscopic evaluation. This is a non-analytic study and descriptive analysis was carried out. Operative procedure and perioperative care we have standardized the steps of Kulkarni panurethroplasty at our institute. All patients are evaluated with a thorough history and examination, uroflowmetery, retrograde and voiding cystourethrogram and where necessary an endoscopic evaluation. Blood tests and urine culture test is carried out.
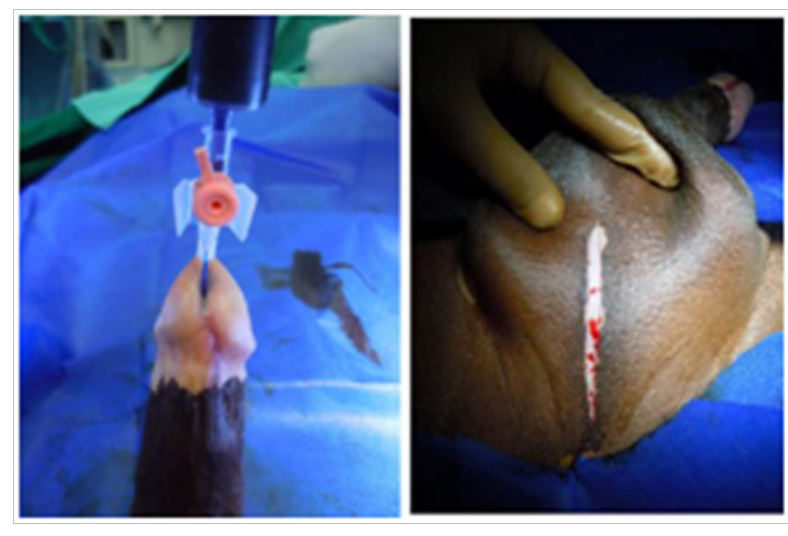

Figure I Methylene blue instillation and perineal incision.

Patient is placed in social lithotomy position with Allen stirrups. Perioperative broad spectrum antibiotics are administered. Small caliber endoscopy is performed to evaluate the urethra. Gide wire is placed and methylene blue is instilled in the urethra. Midline perineal incision in made and layers dissected. (Figure 1) One sided (usually left as the surgeon is right handed) is carried out and the urethra is mobilized. (Figure 2) Penile invagination is performed. (Figure 3) Urethra is opened at 12 o'clock across the stricture. Figures $(4,5)$ Oral mucosal grafts are harvested simultaneously using a second team. Meatotomy is performed. (Figure 6). The grafts are quilted dorsally and urethral closure is performed using absorbable sutures (4.0 vicryl) Grafts are applied from the meatus to the proximal bulbar urethra. Figures $(7,8)$ Closure of the urethra is performed over a size 
14 indwelling urethral catheter. Catheter is left in for 4 weeks and then removed. Pericatheter urethrogram was performed in redo and complex cases. Patient is on low dose oral antibiotics for 4 weeks. Some primary cases with poor urethral plates required a two-stage approach with graft inserted as dorsal inlay in the second stage. In redo cases a ventral approach was chosen with dorsal inlay oral mucosal graft. Figures 9 and 10 depict follow up uroflow and urethrograms. A schematic representation is depicted for easy understanding (Figure 11).

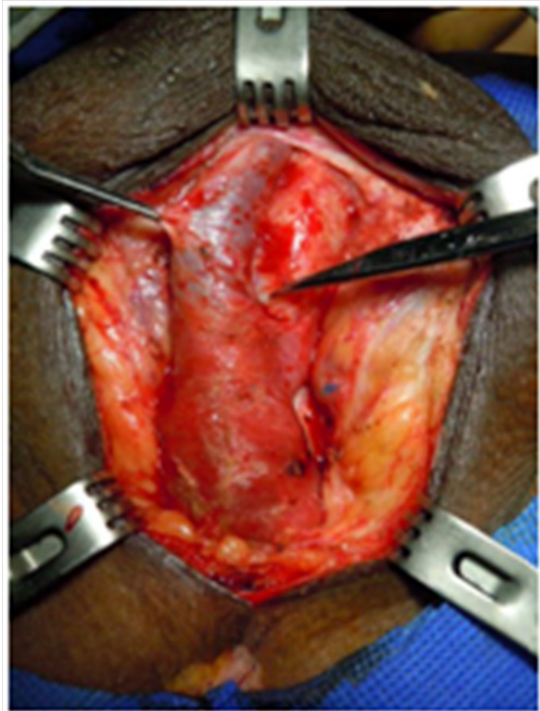

Figure 2 Dissection of urethra -one sided.
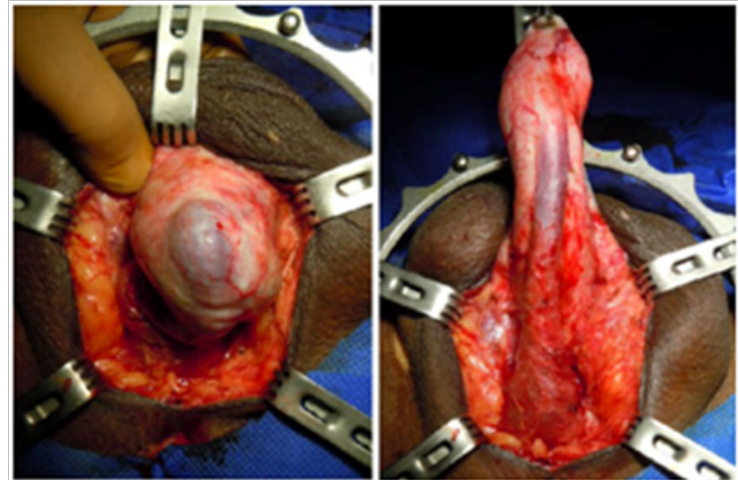

Figure 3 Penile invagination.

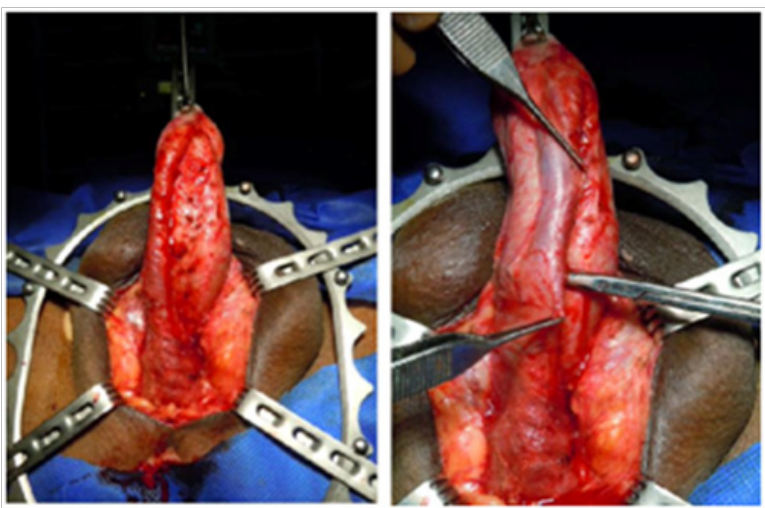

Figure 4 Dissect urethra on one side, other side should remain intact.

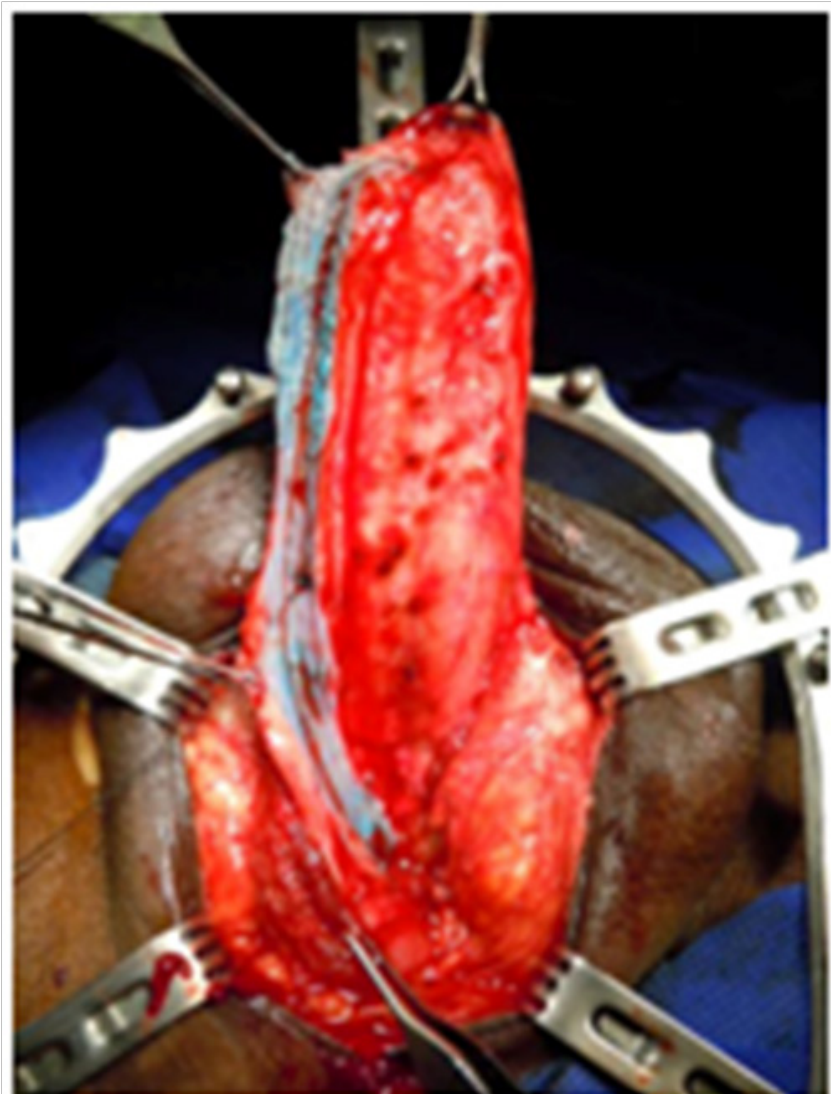

Figure 5 Dorsal spatulation of urethra.
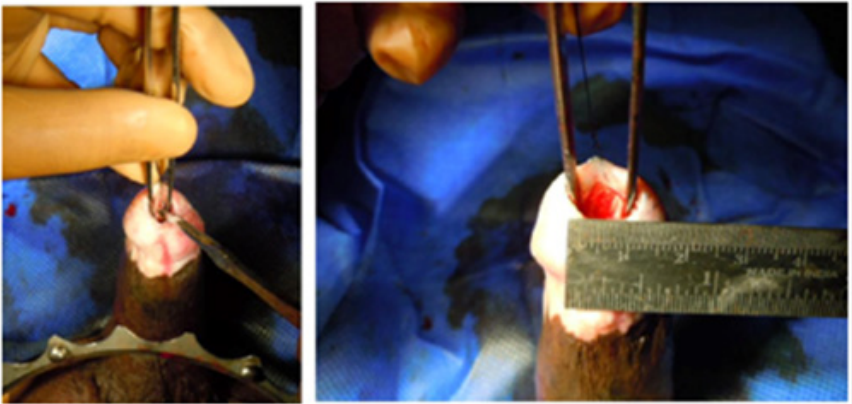

Figure 6 Dorsal Meatotomy.
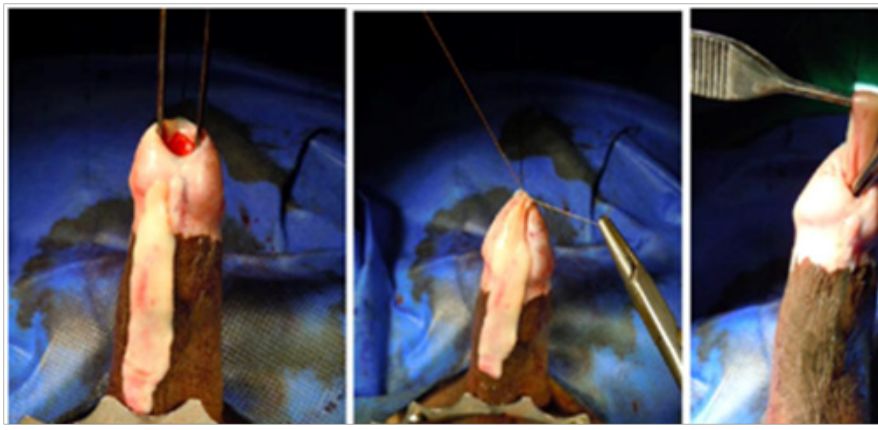

Figure 7 Buccal graft from meatus.

Citation: Desai DJ, Joshi PM, lyer S, et al. Panurethral strictures: a review of management options. Urol Nephrol Open Access. 2017;4(6):204-207. DOI: 10.15406/unoaj.2017.04.00I53 

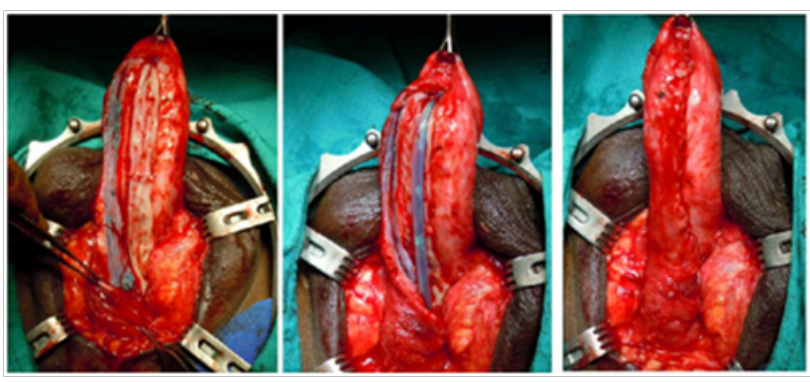

Figure 8 Buccal graft quilted and closure.

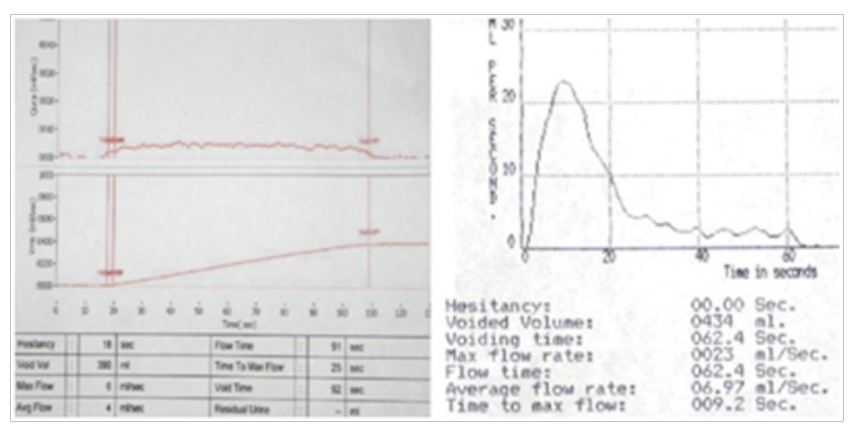

Figure 9 Pre-operative and post-operative uroflow.
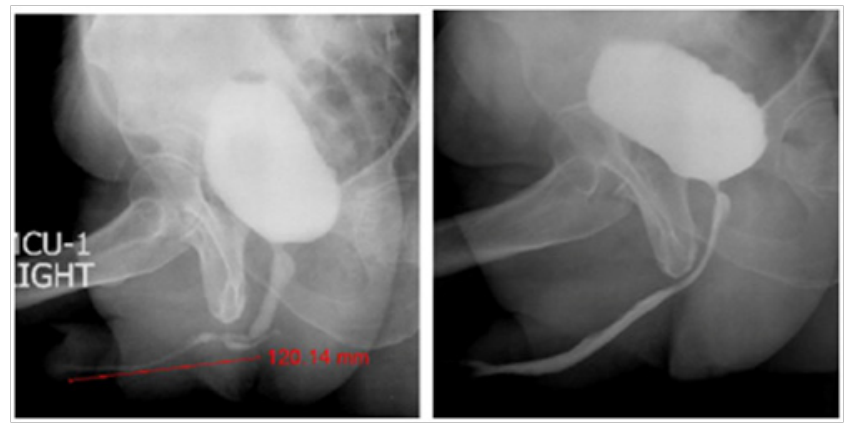

Figure 10 Pre-operative and post-operative urethrogram.

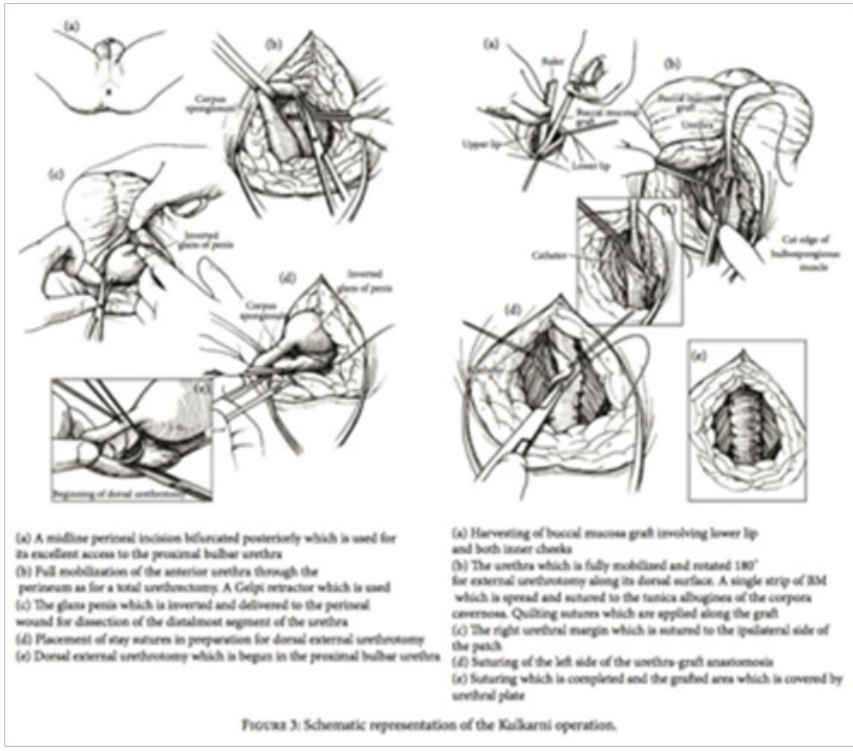

Figure II Schematic Representation of Kulkarni urethroplasty. ${ }^{5}$

\section{Results}

We have performed 318 (283 primary and 35 redo) cases with an average stricture length of $14 \mathrm{cms}$. Lichen sclerosis was seen in $184(57.84 \%)$ cases. Other causes included iatrogenic, traumatic, post failed hypospadias and idiopathic. Age ranged from 20-76 years (median 44.6 years). Our success rate using our management algorithm was $84.9 \%$ (primary cases $89.39 \%$ and redo cases $57.85 \%$ ). Our stringent follow up was at 3,6,9 and 12 months and thereafter every year using uroflow to assess success. Patients with symptomatic poor flow less than $12 \mathrm{ml} / \mathrm{sec}$ and/or urinary tract infections were evaluated further with uroflowmetery, urethrography and endoscopic evaluation.
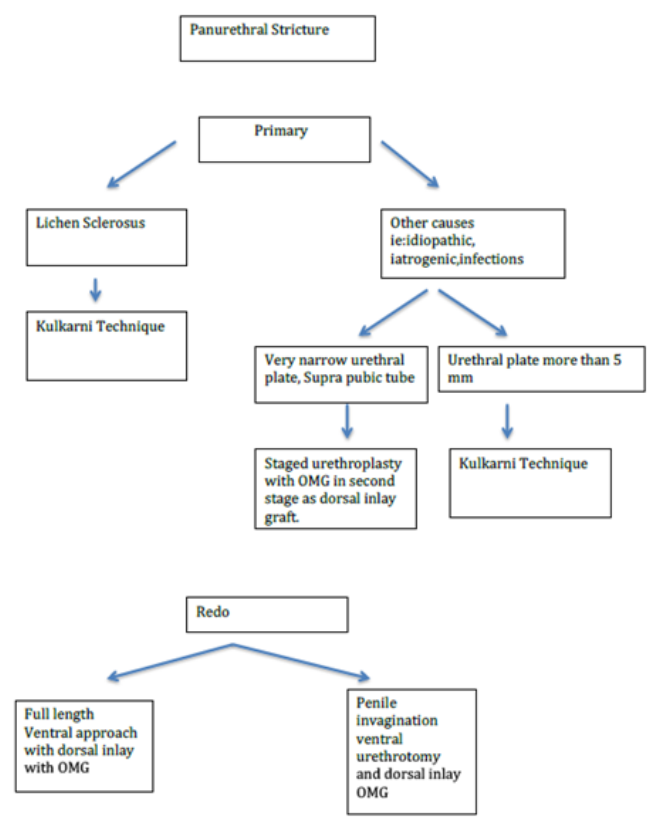

\section{Discussion}

Lichen sclerosis is a chronic condition. Panurethral strictures because of lichen sclerosis present late after a long history of urinary symptoms. On the contrary iatrogenic Panurethral strictures present early. Patients may have undergone several endoscopic procedures prior to being referred for urethroplasty. These patients require standard workup, which includes history, examination for signs of lichen sclerosis, uroflow, ultrasound, blood and urine tests and a retrograde urethrogram. Special attention must be given to oral hygiene, as bilateral long grafts are required for reconstruction. The type of reconstruction depends on etiology, location, length of stricture and whether prior reconstruction was attempted. In primary cases of Panurethral stricture secondary to lichen sclerosis we prefer a single stage one -sided dissection as per Kulkarni technique for reconstruction. If the stricture is due to other causes, the options are Kulkarni technique for those with urethral plate $>5 \mathrm{~mm}$ while we perform staged urethroplasty in patients where there is a deficiency in the urethral plate. In redo cases where there has been a prior failed attempt at reconstruction our approach has been to perform a dorsal inlay oral mucosal graft urethroplasty via a ventral approach and penile invagination. Our grafts are $1.5 \mathrm{~cm}$ wide and about $6-8 \mathrm{~cm}$ long. We leave the graft harvest side open to heal by secondary intention..$^{2,3}$ We have proposed an algorithm for management of panurethral strictures. ${ }^{4}$ 


\section{Conclusion}

We believe that a one stage oral mucosal urethroplasty allows a single procedure with acceptable success in management of this complex condition with improved patient satisfaction as apposed to a multistage approach with the risk of recurrence due to use of genital skin.

\section{Acknowledgments}

None.

\section{Conflicts of Interset}

None.

\section{References}

1. Kulkarni S, Barbagli G, Sansalone S, et al. One- sided anterior urethroplasty: a new dorsal only graft technique. BJU Int. 2009;104:1150 1155 .

2. Kulkarni S, Barbagli G, Kirpekar D, et al. Lichen sclerosus of the male genitalia and urethra: surgical options and results in a multicenter international experience with 215 patients. Eur Urol. 2009;55(4):945954.

3. Kulkarni SB, Barbagli G. One-sided anterior urethroplasty: a new dorsal onlay graft technique. J Urol Suppl. 2010;183:e593.

4. Kulkarni SB, Kulkarni JS, Surana S, et al. Management of Panurethral Stricture. Urol Clin N Am. 2017;44(2017):67-75.

5. Martins FE, Kulkarni SB, Joshi PM, et al. Management of Long-Segment and Panurethral Stricture Disease. Adv Urol. 2015;2015:853914. 